\title{
Sensorless Direct Torque Control of the Six-Phase Induction Motor by Fast Reduced Order Extended Kalman Filter
}

\author{
Asghar Taheri $\mathbb{D}^{1,2}$ Hai-Peng Ren $\mathbb{D}^{1,3}$ and Chun-Huan Song ${ }^{1}$ \\ ${ }^{1}$ Xi'an Key Laboratory of Intelligent Equipment, Xi'an Technological University, Xi'an 710021, China \\ ${ }^{2}$ University of Zanjan, Zanjan 4537138791, Iran \\ ${ }^{3}$ Shaanxi Key Laboratory of Complex System Control and Intelligent Information Processing, Xi'an University of Technology, \\ Xi'an 710048, China \\ Correspondence should be addressed to Hai-Peng Ren; renhaipeng@xaut.edu.cn
}

Received 4 January 2020; Revised 7 May 2020; Accepted 18 June 2020; Published 1 October 2020

Academic Editor: Guang Li

Copyright (c) 2020 Asghar Taheri et al. This is an open access article distributed under the Creative Commons Attribution License, which permits unrestricted use, distribution, and reproduction in any medium, provided the original work is properly cited.

\begin{abstract}
In this paper, a simple extended Kalman Filter (EKF) controller for direct torque control (DTC) of a six-phase induction machine in all speed ranges is proposed. The aim of this paper is to decrease the execution time of EKF modeling of a six-phase induction motor. The proposed method is fast and can operate online. If the machine parameters are changed during the operation, the EKF algorithm is activated to find parameters used for controlling the motor. In low speed, not only the motor speed measurement but also the DTC of machine is difficult. The EKF model can estimate speed, flux, load torque, and stator resistance in low speed; thus, optimization can be performed in all loads and speed range. The proposed method increases the accuracy of DTC of the six-phase induction machine and decreases the computation cost of the system using the simplified algorithm. The simulation and experimental results verify the effectiveness and the robustness of the proposed method against parameter variations.
\end{abstract}

\section{Introduction}

Six-phase and five-phase machines are two usual types of multiphase machines that are used in several applications [1-4]. Increasing of machine phases causes some advantages such as higher redundancy and decreasing torque pulsation [5-7]. Field-oriented control (FOC) and direct torque control (DTC) techniques are implemented to speed control of six-phase and five-phase machines [8-11]. These methods have no very satisfactory response in low-speed applications. In low-speed applications, it needs a suitable method for parameters and speed estimation. DTC method is a simple and robust method against parameter variations. This method has very fast dynamic response in load variations. Thus, this method is used in many industrial applications. DTC is a powerful method in control of several types of AC machines. This method has a good response in control of sixphase and five-phase induction machines [12]. One of the major errors of the DTC method is caused by the variation of stator resistance, which is more serious in low-speed conditions. Stator resistance is changed with varying the motor temperature. If stator resistance change is not considered in the DTC method, then it causes an error in controller outputs [13-16]. Thus, to increase the accuracy of the DTC method, it needs a suitable method to estimate stator resistance [14]. To estimate stator resistance, several methods are used in literatures. Antonello et al. [17] proposed a new method for online estimation of the stator resistance $\left(R_{s}\right)$, which is suitable to anisotropic motors. It is demonstrated that this method measures the stator resistance without information about motor parameters, and the signal-tonoise ratio (SNR) is improved. A suitable method to estimate the stator resistance based on the mechanical loss and torque is proposed in the study by Salomon et al. [18]. This method is suitable to offline estimate of resistance and in service applications of the induction motor. This paper uses a particle swarm optimization (PSO) algorithm based on flux equations with minimizing the torque error. An analytical method to estimate the stator resistance of a synchronous motor and DTC based on this method is proposed in the study by Sangsefidi et al. [19]. This method uses the effect of a stator resistance error on the estimated angle between stator 
flux and current vectors. Winding temperature in a dual threephase machine is estimated with a DC signal injection in the study by Baneira et al. [20]. This signal is injected in the $\left(z_{1}-z_{2}\right)$ subspace to cancel the torque ripple and air gap flux. This method can only be used in a multiphase machine with this type of freedom in modeling. The problem of $R_{s}$ and $R_{r}$ identification in a sensorless IM is proposed in the study by Yin et al. [21]. This paper uses a first order approximation of the error dynamics in an adaptive observer. The induction motor included only the known signals; thus, this method is feasible. The stator resistance estimation based on a phase-shift compensator is presented in the study by Barut et al. [22]. This method is decoupled with the speed estimator by an operatingpoint-tracking compensation coefficient.

Extended Kalman filter (EKF) is a powerful estimator to estimate not only the stator resistance but also to load torque and flux of the machine [23-29]. This method is used in several papers to estimate the machine parameters. This method is suitable to estimate parameters of machine with load and parameter variations [25-28]. Nowadays, with the increase of processing speed in DSP, online experiment of EKF is possible. Induction motor has stochastic properties; thus, the EKF can be easily used to model it. Also, it can be used to control of the machine when the machine is used in the low speed or machine parameters are varied. Other estimators are used for parameter estimation of induction machine parameters [30-33]. EKF is used to model a sixphase induction machine with powerful results $[34,35]$.

A simple extended Kalman filter (EKF) loss model controller (LMC) for efficiency improvement of a six-phase induction machine in all speed ranges is proposed [36]. The proposed method is fast and can be operated online. If the machine parameters are changed during the operation, the EKF algorithm is activated to find the parameters to ensure optimal efficiency operation. The EKF model can estimate speed, load, and motor efficiency at low speed ranges, so that optimization can be performed in all loads and speed ranges. Unlike the conventional LMC method, the proposed method is independent of parameter variations [36].

Multirate parameter and state estimation methods for the induction motor based on EKF theory is proposed for load torque estimation in the induction motor. The methods are implemented in real-time on PC cluster node, which acts as the controller for an induction motor experimental setup. A multirate model reference adaptive system (MRAS) is proposed to estimate the rotor time constant in order to guarantee the high-performance control of the induction motor [37].

The temperature-dependent variation of the stator and rotor resistances, which induce a large estimation error on speed and flux, has been a critical issue for the speed-sensorless control. To estimate simultaneous variations of the stator and rotor resistances in the speed-sensorless control of IMs under different operating conditions, an estimator is developed based on the extended Kalman filter (EKF) technique. In order to resolve the instability issue of simultaneous estimation of stator and rotor resistances, the stator resistance is estimated via consideration of its temperature dependence and the thermal dynamics of the stator windings, whereas the rotor resistance is estimated as a constant state [38]. The DTC of IM drive with EKF to estimate stator stationary axis components of stator currents, stator fluxes, stator, and rotor resistances with the assumption of available stator voltages/currents and rotor speed is presented in the study by Demir et al.[39]. The online estimations of rotor and stator resistances have a good response by using a single EKF algorithm and a speedsensor [39].

Suitable EKF estimator is proposed for accurate flux and speed estimation at very low and zero speed. This technique is applied with speed-sensorless direct vector control and two EKF algorithms, by switching from one algorithm to another at each sampling time. The switching method needs accurate and increased number of parameters estimation. The transient and steady state estimation of rotor and stator resistances is an important challenge in speed-sensorless IM control that is reported in the study by Barut et al. [40].

The aim of this paper is to decrease the execution time of EKF modeling of a six-phase induction motor. The proposed method increases accuracy and decreases the computation cost of the system. Also, the accuracy of DTC of the sixphase induction machine is improved with the stator resistance estimation. The proposed method used a suitable EKF algorithm to estimate flux and load torque. The accuracy of the DTC method is improved with an online stator resistance estimator. The EKF modeling of 6PIM is accurate and robust against the parameter variations. This paper presents a suitable DTC of 6PIM in all speed ranges. If the load is changed, the EKF algorithm estimates load and speed quickly and accurately. Also, the presented algorithm is robustness against resistance change. Estimation of speed is a powerful tool in speed calculation in all speed ranges because speed calculation of the motor in low and zero speed is extremely difficult and with errors.

In this paper, six-phase induction motor modeling and DTC of 6PIM are deduced, first. The EKF modeling of 6PIM is described in the next section. A suitable DTC of 6PIM that used parameter estimation of EKF is described. Finally, simulation results of proposed methods are shown, and then, experimental results validate the correctness of proposed methods in all speed ranges.

\section{Six-Phase Induction Motor Model}

2.1. Modeling and DTC of the Six-Phase Induction Motor. Vector space decomposition method (VSD) is used in modeling of 6PIM. With this method and applying $6^{*} 6$ matrices, the six-phase voltage, current, and flux equations are transformed to three subspaces. These subspaces are named as $(\alpha-\beta),\left(z_{1}-z_{2}\right)$, and $\left(O_{1}-O_{2}\right)$. The motor flux is produced with the main harmonics current and voltage that are mapped to $(\alpha-\beta)$ subspace. The DTC of 6PIM is implemented in $(\alpha-\beta)$ subspace, and other current subspaces references are set to be zero. Because the harmonics mapped to the $\left(z_{1}-z_{2}\right)$ and $\left(O_{1}-O_{2}\right)$ only produce loss and are considered as zero in various control methods. 6PIM modeling with the VSD method is shown in the following equations. All motor symbols are stated in Table 1. 
TABLE 1: Motor parameters.

\begin{tabular}{lc}
\hline $\mathrm{Rs}$ & $15.0 \Omega$ \\
$\mathrm{Rr}$ & $7.91 \Omega$ \\
Motor and load moment & $5.2 * 10^{-3} \mathrm{kgm}^{2}$ \\
$\mathrm{Ls}$ & $603.3 \mathrm{mH}$ \\
$\mathrm{Lr}$ & $604.3 \mathrm{mH}$ \\
$\mathrm{Lm}$ & $589.1 \mathrm{mH}$ \\
\hline
\end{tabular}

$$
\begin{aligned}
\overrightarrow{V_{s}} & =R_{s} \overrightarrow{I_{s}}+\frac{\mathrm{d} \overrightarrow{\Psi_{s}}}{\mathrm{~d} t}, \\
0 & =R_{r}{\overrightarrow{I_{r}}}+\frac{\mathrm{d} \overrightarrow{\Psi_{r}}}{\mathrm{~d} t}-j \omega_{e} \vec{\Psi}_{r}
\end{aligned}
$$

The dynamic model of the six-phase induction motor in $(\alpha-\beta)$ subspace can be shown as

$$
\begin{aligned}
& \left\{\begin{array}{l}
\frac{\mathrm{d} X}{\mathrm{~d} t}=A(x)+B U+\omega_{1}, \\
Y=C X+\omega_{2} .
\end{array}\right. \\
& X=\left[\begin{array}{lllllll}
I_{s \alpha} & I_{s \beta} & \Psi_{s \alpha} & \Psi_{s \beta} & \omega_{r} & R_{s} & T_{l}
\end{array}\right], \\
& Y=\left[\begin{array}{ll}
I_{s \alpha} & I_{s \beta}
\end{array}\right], \\
& U=\left[\begin{array}{ll}
u_{s \alpha} & u_{s \beta}
\end{array}\right] \text {. }
\end{aligned}
$$

$X$ is the state vector of the system, $Y$ is the measured parameter of the motor, and $U$ is the input vector in $(\alpha-\beta)$ subspace. All noise of the system is $\omega_{1}$, and measurement equipment in that subspace is $\omega_{2}$.

$$
A_{C}(x)=\left[\begin{array}{ccccccc}
A_{11} & -\omega_{r} & A_{13} & A_{14} \omega_{r} & 0 & 0 & 0 \\
\omega_{r} & A_{22} & A_{23} \omega_{r} & A_{24} & 0 & 0 & 0 \\
-R_{s} & 0 & 0 & 0 & 0 & 0 & 0 \\
0 & -R_{s} & 0 & 0 & 0 & 0 & 0 \\
0 & 0 & 0 & 0 & 0 & 0 & 0 \\
0 & 0 & 0 & 0 & 0 & 0 & 0 \\
0 & 0 & 0 & 0 & 0 & 0 & 0
\end{array}\right] .
$$

While

$$
\begin{aligned}
A_{11} & =A_{22}=-\left(\frac{R_{s}}{\sigma L_{s}}+\frac{R_{r}}{\sigma L_{r}}\right), \\
A_{13} & =-A_{24}=\frac{R_{r}}{\sigma L_{s} M}, \\
A_{14} & =-A_{23}=\frac{\omega}{\sigma L_{s}}, \\
k_{T} & =\frac{3}{2 J}, \\
B_{c} & =\left[\begin{array}{llllll}
\frac{1}{\sigma L_{s}} & 0 & 1 & 0 & 0 & 0 \\
0 & \frac{1}{\sigma L_{s}} & 0 & 1 & 0 & 0
\end{array}\right], \\
C_{c} & =\left[\begin{array}{lllllll}
1 & 1 & 0 & 0 & 0 & 0
\end{array}\right] .
\end{aligned}
$$

All noise of the drive system and measurement equipment in that subspace are modeled with $w_{1}^{\prime}$ and $w_{2}^{\prime}$. The suitable discrete model of the motor is needed to the DSPbased control of the motor. The discrete model of 6PIM is deduced by discretizing of the state vectors. If the sampling time is $T_{s}$, the discrete state vector in $(\alpha-\beta)$ subspace is

$$
\left\{\begin{array}{l}
x(k)=A_{d}(x) x(k)+B_{d}(k)+\omega_{1}(k), \\
y(k)=C_{d}(k)+\omega_{1}(k),
\end{array}\right.
$$

where $A_{d}(x)=A_{c}(x) T_{s}+I_{7 * 7}, B_{d}=B_{c} T_{s}$, and $C_{d}=C_{c}$.

2.2. Reduced Order EKF Modeling of 6PIM. When speed is low, the speed sensors quality is much decreased. EKF is a powerful estimator that can be used to increase the accuracy of estimation. The output of EKF is used with both sections with a real-time response. The EKF model of the six-phase induction motor can be indicated by recursive equations as below:

$$
\begin{gathered}
P(k)=A_{\mathrm{dd}}(\hat{x}(k)) P_{h}(k) A_{\mathrm{dd}}^{T}(\widehat{x}(k))+B_{\mathrm{dd}}(u(k)) w_{u}(k) B_{\mathrm{dd}}^{T}(u(k))+Q(k), \\
P_{h}(k+1)=P(k)-P(k) C_{d}^{T}(k)\left(C_{d}(k) P(k) C_{d}^{T}(k)+R\right)^{-1} C_{d}(k) P(k), \\
\widehat{x}_{h}(k+1)=A_{d}(\widehat{x}) \widehat{x}(k)+B_{d} u^{T}(k)+P_{h}(k+1) C_{d}^{T}(k) R^{-1}\left(Y_{y}^{\prime}-C_{d}(k) \widehat{x}(k)\right),
\end{gathered}
$$

where $A_{d d}(\hat{x}(k))=\left(\partial A_{d}(\hat{x}(k)) / \partial(\hat{x}(k))\right)$, and $B_{d d}(u(k))=$ $\left(\partial B_{d}(u(k)) / \partial u(k)\right)$.

Three covariance matrices $\left(Q, R\right.$, and $\left.w_{u}\right)$ are used to model the system, measurement, and input noise of the system. Above equations are run recursively to decrease the estimation error. Because the above EKF algorithm needs a large time to execute, the EKF model can be simplified as follows: 


$$
\left[\begin{array}{c}
\hat{x}_{1}(k+1) \\
\bar{x}_{2}(k+1)
\end{array}\right]=T_{s}\left[\begin{array}{cccc}
A_{11} & -x_{5} & A_{13} & A_{14} x_{5} \\
x_{5} & A_{21} & A_{23} x_{5} & A_{24}
\end{array}\right]\left[\begin{array}{c}
\hat{x}_{1} \\
\hat{x}_{2} \\
\hat{x}_{3} \\
\bar{x}_{4}
\end{array}\right]+\frac{T_{s}}{\sigma L_{s}}\left[\begin{array}{c}
v_{s \alpha} \\
v_{s \beta}
\end{array}\right]
$$

$\left\{\begin{array}{l}\widehat{x}_{3}(k+1)=-R_{s} \widehat{x}_{1} T_{s}+\widehat{x}_{3}+v_{s \alpha}, \\ \widehat{x}_{4}(k+1)=-R_{s} \widehat{x}_{2} T_{s}+\widehat{x}_{4}+v_{s \beta},\end{array}\right.$

$$
\widehat{x}_{5}(k+1)=T_{s}\left[\begin{array}{lll}
-k_{T} \widehat{x}_{4} & k_{T} \bar{x}_{3} & -\frac{1}{J}
\end{array}\right]\left[\begin{array}{l}
\hat{x}_{1} \\
\bar{x}_{2} \\
\bar{x}_{6}
\end{array}\right]+\widehat{x}_{5},
$$

$A_{\mathrm{dd}}(x)=\left[\begin{array}{cccccc}A_{11} T_{s}+1 & -\widehat{\omega}_{r} T_{s} & A_{13} T_{s} & A_{14} \widehat{\omega}_{r} & \widehat{i}_{s \beta} T_{s}+A_{14} \widehat{\psi}_{s \beta} T_{s} & 0 \\ \widehat{\omega}_{r} T_{s} & A_{22} T_{s}+1 & A_{23} \widehat{\omega}_{r} T_{s} & A_{24} T_{s} & \widehat{i}_{s \alpha} T_{s}+A_{14} \widehat{\psi}_{s \alpha} T_{s} & 0 \\ -k_{T} \widehat{\psi}_{s \beta} T_{s} & k_{T} \widehat{\psi}_{s \alpha} T_{s} & k_{T} \widehat{i}_{s \beta} T_{s} & -k_{T} \hat{i}_{s \alpha} T_{s} & 1 & A_{56}\end{array}\right]$,

$$
\begin{aligned}
P_{\mathrm{Ph}(i, j=1, \ldots, 3)} & =P_{h} A_{\mathrm{dd} 1}^{\prime}, \\
P_{\mathrm{Ph}(i, 4)} & =P_{h(i, 1)}\left(-R_{s} T_{s}\right)+P_{h(i, 4)}, \\
P_{\mathrm{Ph}(i, 5)} & =P_{h(i, 2)}\left(-R_{s} T_{s}\right)+P_{h(i, 5)}, \\
P_{\mathrm{Ph}(i, k)} & =P_{h(i, k)}, \quad i=1, \ldots, 7, k=6,7 .
\end{aligned}
$$$$
P_{(i=1, \ldots, 3, j)}=A_{\mathrm{dd} 1} P_{\mathrm{Ph}} \text {, }
$$$$
P_{(4, j)}=P_{\mathrm{Ph}(j, 1)}\left(-R_{s} T_{s}\right)+P_{\mathrm{Ph}(j, 4)},
$$$$
P_{(5, j)}=P_{\mathrm{Ph}(j, 2)}\left(-R_{s} T_{s}\right)+P_{\mathrm{Ph}(j, 5)} \text {, }
$$$$
P_{(k, j)}=P_{\operatorname{Ph}(k, j)}, \quad k=6,7 j=1, \ldots, 7 .
$$

Proposed reduced order EKF modeling of the six-phase induction machine can be used to decrease the execution time of EKF modeling of the motor. In the proposed method, the execution time is reduced, and also, the complexity of the system is reduced. Diagram of proposed reduced order EKF (ROEKF) modeling of DTC of the sixphase induction motor is shown in Figure 1.

Dynamic performance of EKF and ROEKF is related to $Q$ and $R$ initial values. By changing these parameters, the Kalman filter response will be improved somewhat. An EKF estimator has a big primary error in the start time that is related to $Q$ and $R$ matrix and is adjustable with initial values. Also, if initial values of the state matrix will be near to real values, dynamic response of the estimator is improved. In this paper, initial values of parameters are considered to be uncertain and are estimated independently from initial values.

In deferent applications, the EKF estimator is often tuned to have constant parameter matrices. In an EKF estimator, $Q$ quantifies the system modeling inaccuracies, and $R$ quantifies the measurement noises prevailing in the system. A low $Q$ leads to a slow transient response, and a high $Q$ leads to a high noise in steady state resistance estimates. According to reviewer suggestion, we use an adaptive tuning that varies the $Q$ matrix as a function of estimate error, whereby a high value of $Q$ is chosen in the transients, a low value in the steady state, and a linear variation is ensured between the limits. Adaptive tuning of EKF is reported in the literatures to be realized using various adaptation mechanisms for $Q$ and $R$ matrices, based on the reduction of estimated noise levels. In this paper, we use a simple adaptation mechanism suitable for DTC of a machine. The settling time of the observer must be lower than the settling time of the controller, in alternative terms. In the used adaptive technique, the $Q$ matrix is varied to certain limit values, which does not compromise the convergence of the filter, and hence has no adverse effects on the bandwidth of the controller.

These parameters were chosen on the basis of the closedloop performance and computation cost of the algorithm. The values of system parameters and covariance matrix elements are very effective on the performance of the EKF estimation. In this paper, to avoid computational complexity, the covariance matrix of the system noise $Q$ is chosen in a diagonal form, also satisfying the condition of positive definiteness. According to the KF theory, the $Q$ and $R$ matrices have to be obtained by considering the stochastic properties of the corresponding noises. However, since $Q$ and $R$ are usually not known, in most cases, the covariance matrix elements are used as weighting factors or tuning parameters. In general, while the tuning of the initial values of $P$ (estimation error covariance matrix) and the $Q$ is performed by experimental trial-and-error to achieve a rapid initial convergence and the desired transient and steady state behaviors, $Q$ and $R$ are determined taking into account the measurement errors of the current and voltage sensors and the quantization errors of the ADCs.

In implementing the Kalman filter method, some of the calculation only increases the computation time, although they do not result in parameter estimation, largely accounting for the amount of CPU computation. The required code memory is increased slightly but the required data memory is reduced in the proposed method. Also, reducing the computational time will increase the accuracy of the proposed algorithm and reduce the implementation cost. With state vector as (4), in the previous EKF methods, all matrix dimensions would be selected as six. For example, matrix $P$ has $6 * 6$ dimensions, but in the proposed method, the matrix dimension is selected as (16). If state vector has eight variables, the proposed method decreases the execution time near to a quarter. This means $75 \%$ decrease in calculation. With reduction of the EKF calculation, the selected sample time is decreased.

\section{Simulation and Experimental Results}

In this section, first, ROEKF performance for parameter estimation in 6PIM is shown in Figures 2 and 3. In these simulations, motor speed reference is $50 \mathrm{rad} / \mathrm{sec}$ and $2 \mathrm{rad} /$ sec, respectively. The EKF algorithm is active and estimates all states. According to this figure, the stator resistance is changed at $6 \mathrm{sec}$, and the load is varied at $2 \mathrm{sec}$ and then 5 second, but the EKF algorithm can estimate these variations 


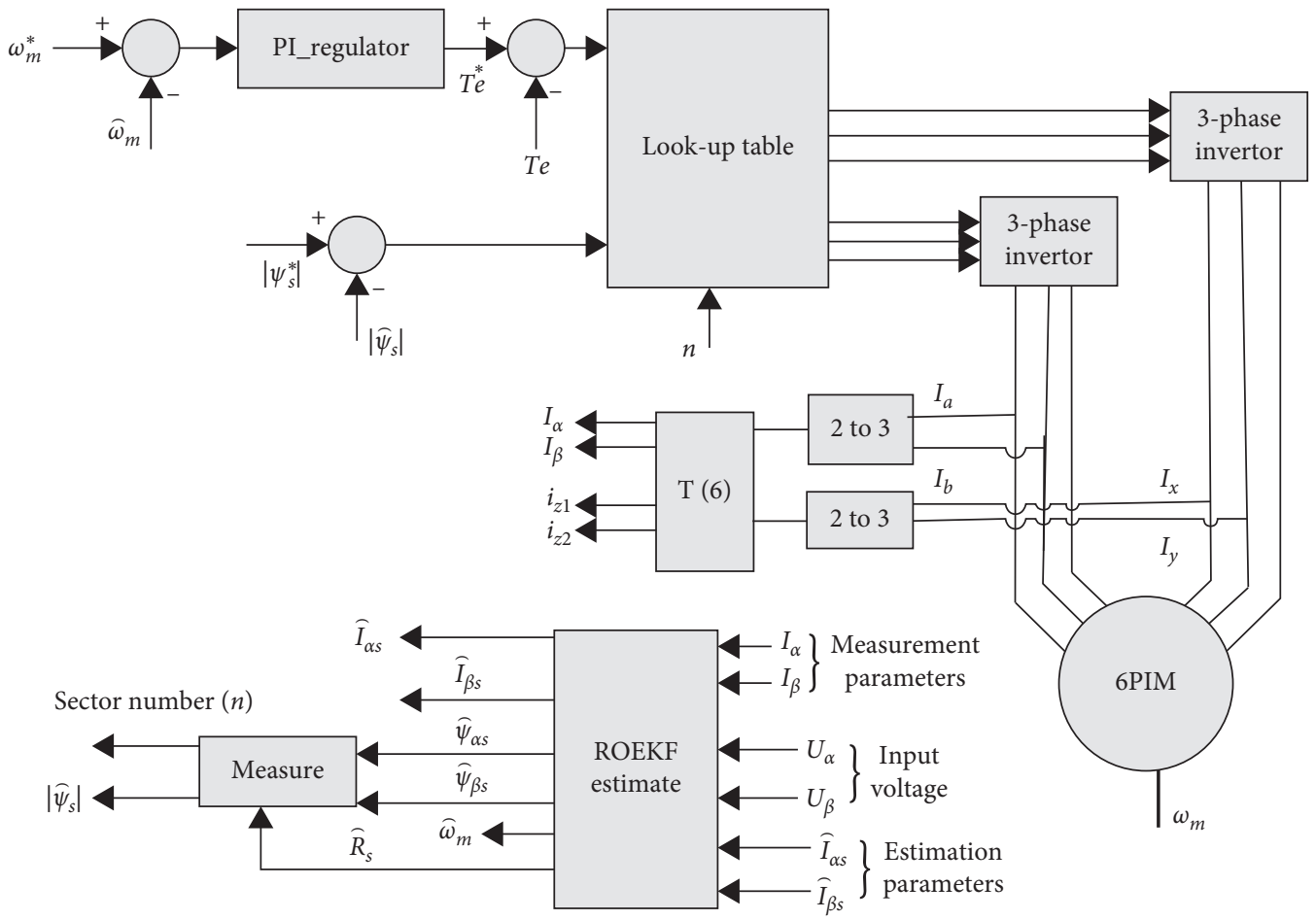

FIGURE 1: Diagram of reduced order EKF modeling of DTC of the six-phase induction motor.
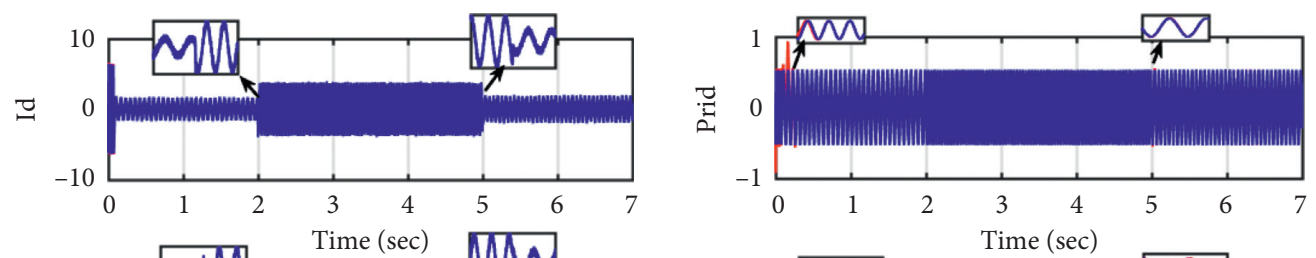

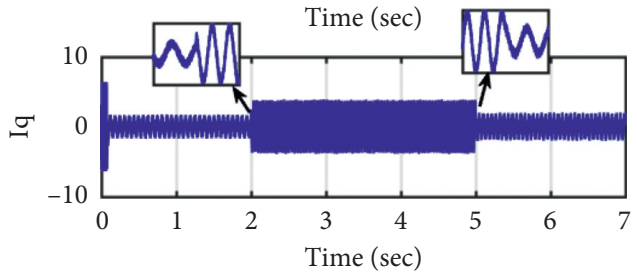

(a)

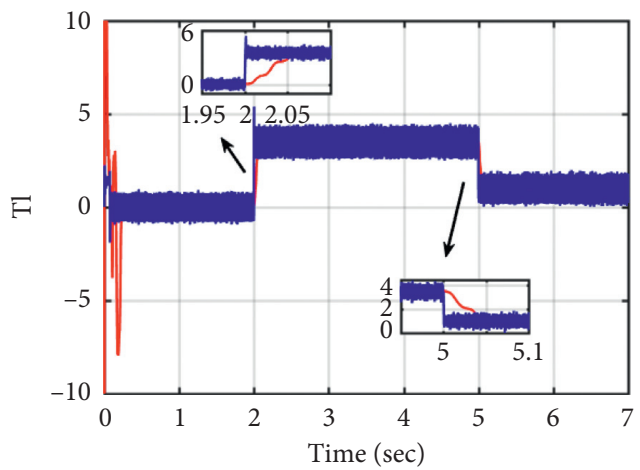

(c)

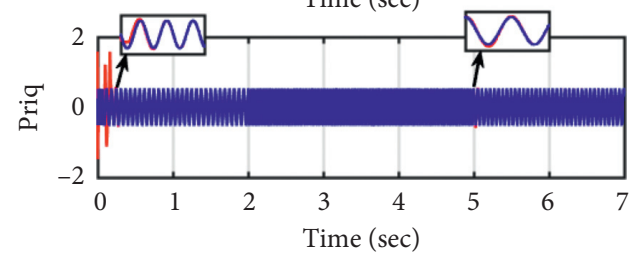

(b)

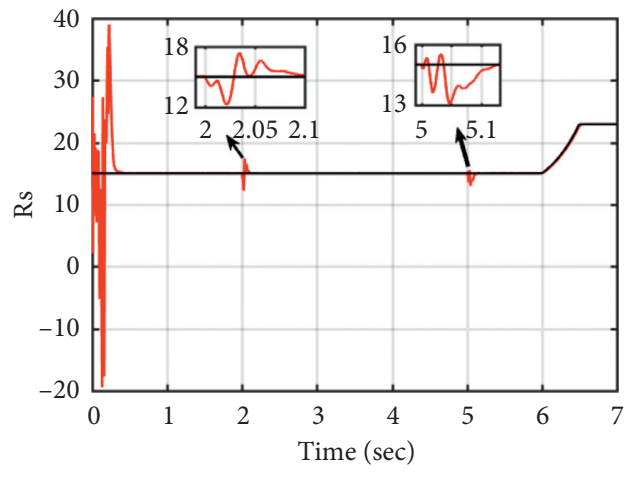

Estimation

Real value

(d)

FIgure 2: Continued. 


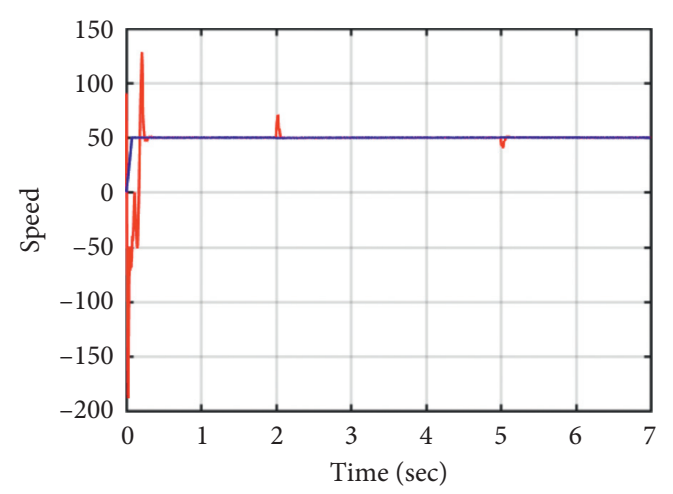

(e)

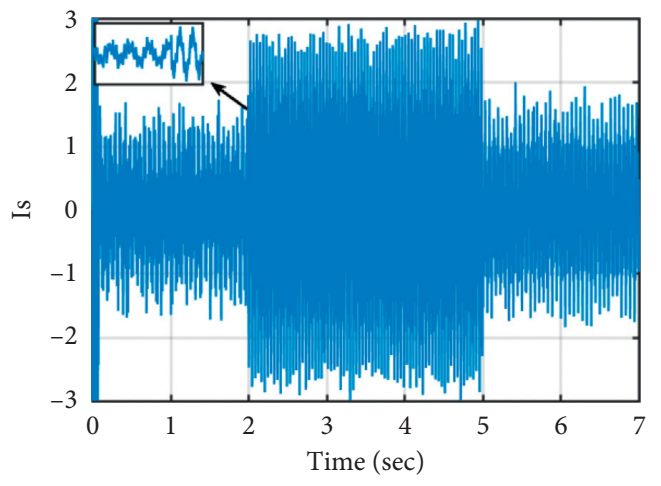

(f)

FIgURE 2: EKF modeling of the six-phase induction motor in $50 \mathrm{rad} / \mathrm{sec}$.
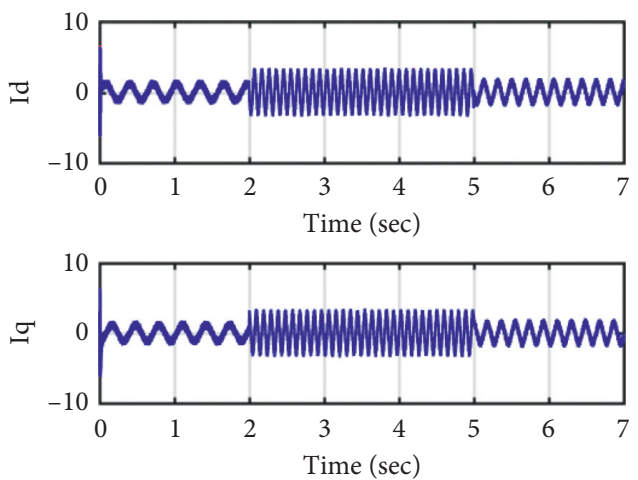

(a)

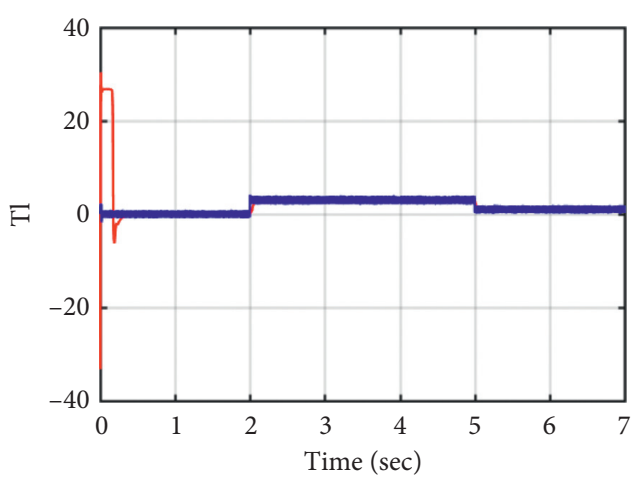

(c)

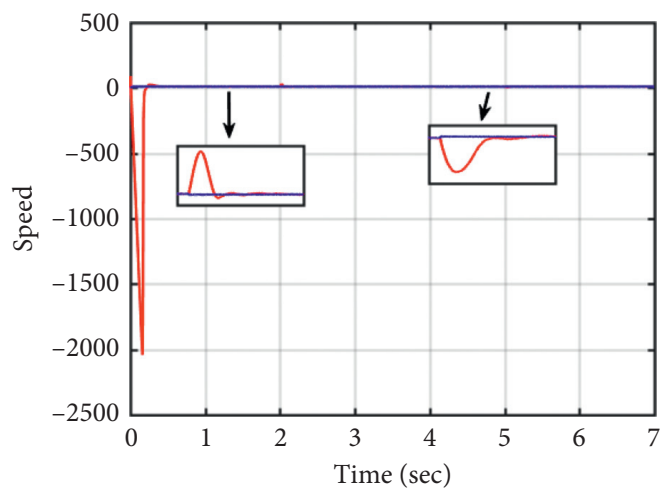

(e)
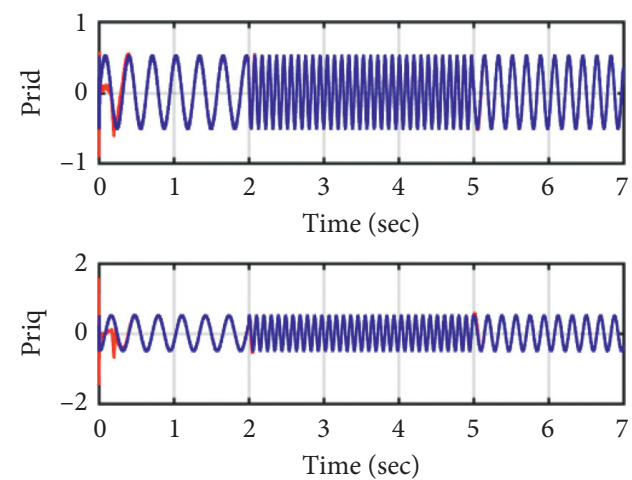

(b)

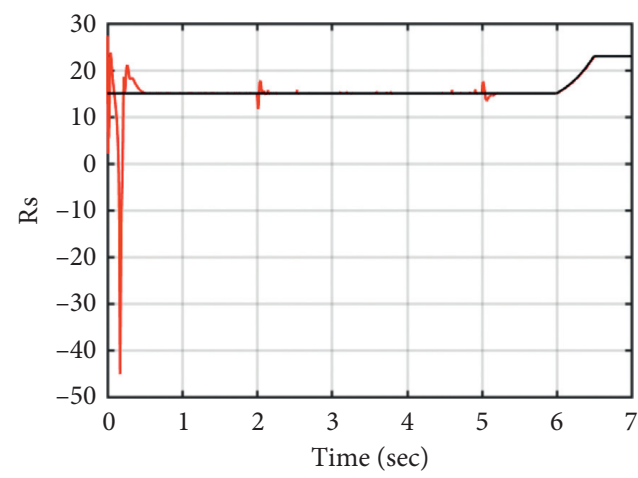

(d)

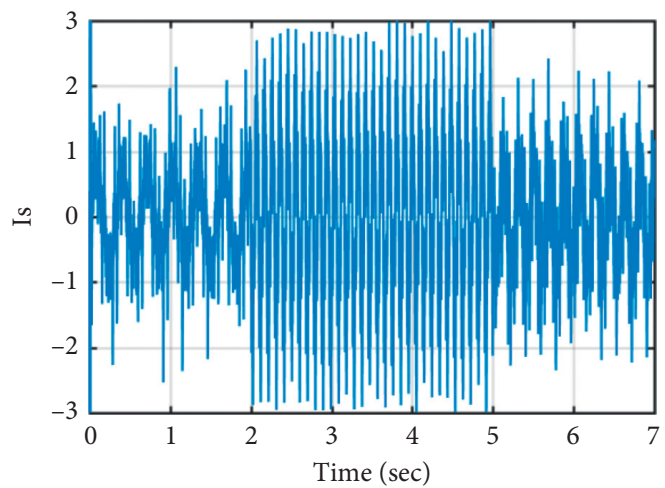

(f)

FIGURE 3: EKF modeling of the six-phase induction motor in low speed. 


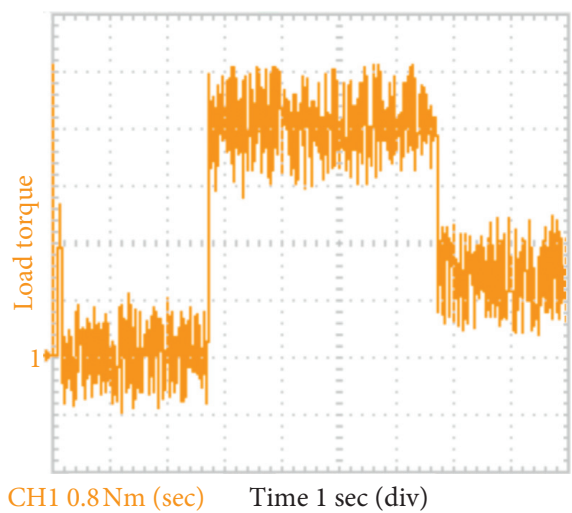

(a)

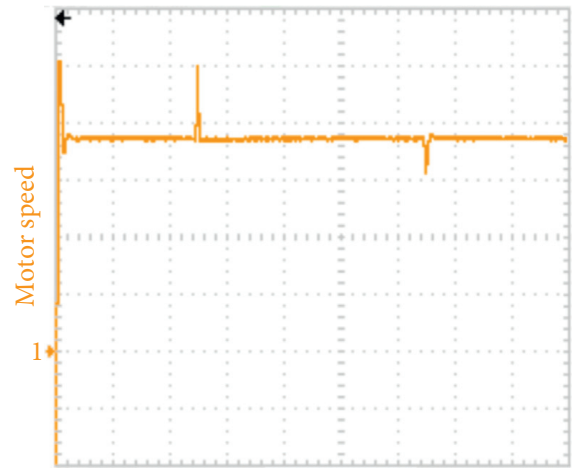

CH1 13.5 rad (sec) Time $1 \mathrm{sec}$ (div)

(c)

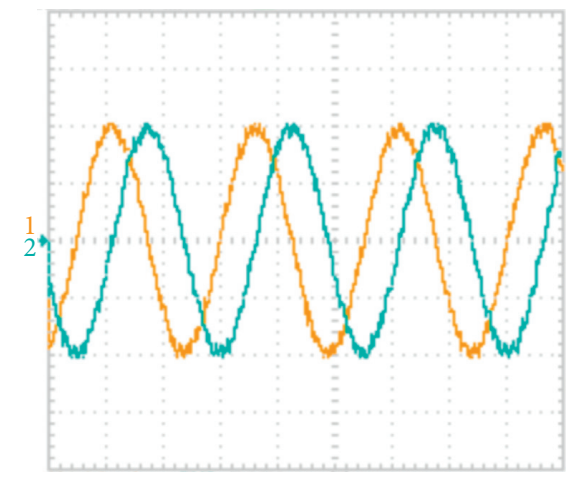

CH1 0.25 web CH2 0.25 web M20 ms

(e)

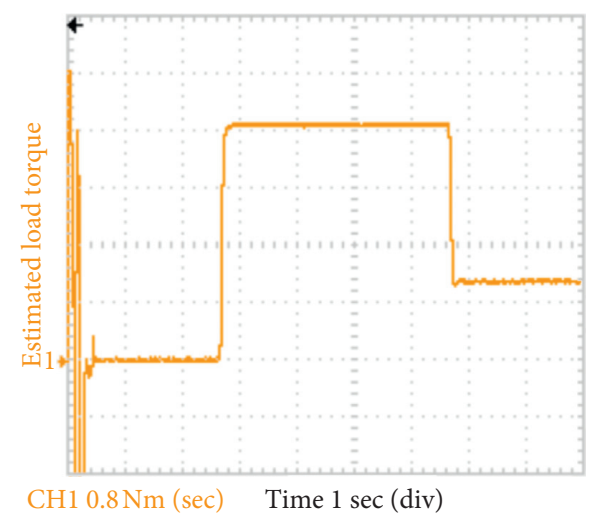

(b)

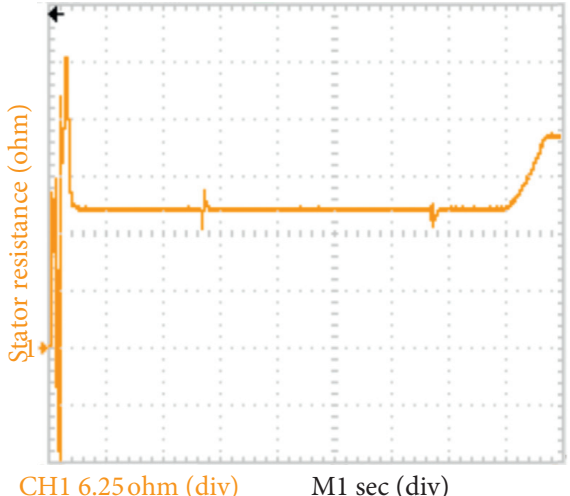

(d)

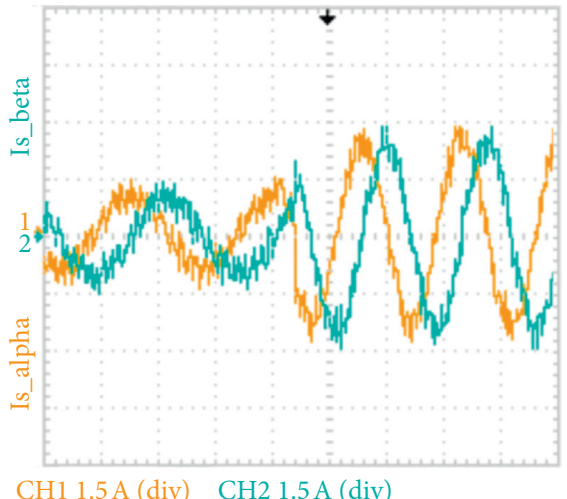

(f)

FIGURE 4: Experimental results of EKF modeling of the six-phase induction motor in (a) load torque, (b) estimated load torque, (c) estimated motor speed, (d) estimated stator resistance, (e) zoomed shape of stator flux, and (f) zoomed shape of stator current.

very well. Figure 2 shows the stator current, flux, stator resistance, load torque, and speed estimation of the sixphase induction motor at $50 \mathrm{rad} / \mathrm{sec}$. According to Figure 2, the load torque is $0.1 \mathrm{Nm}$ in the start time and varied to $4.5 \mathrm{Nm}$ at $2 \mathrm{sec}$. According to results, proposed method has good response, and estimation error is low.

Figure 3 shows the parameter estimation results in ROEKF in low speed condition. In this figure, the motor speed is $1 \mathrm{rad} / \mathrm{sec}$, and the proposed method can estimate all parameters completely in low speed. In Figure 3, the load torque is $0.1 \mathrm{Nm}$ in the start time and varied to $4.5 \mathrm{Nm}$ at 2 sec. Figure 3 shows current and flux in (d-q) axes, load torque, stator resistance, motor speed, and phase current estimation. According to results, the proposed ROEKF technique is active with load and stator resistance variations and can estimate real values fast and accurately. Accuracy of the DTC method is closely related to accurate estimation of stator resistance. The DTC method is highly dependent on the actual amount of stator resistance, and any error in calculating the resistance will cause this method to fail. The dependence of the DTC method on the actual value of resistance is very high, especially at low speeds. Any error in the actual value of the stator resistor will cause an error in the control and instability of the system. 
TABle 2: Comparison of math functions in EKF and ROEKF methods.

\begin{tabular}{lcc}
\hline & EKF & ROEKF \\
\hline Multiplications & 2212 & 889 \\
Additions & 2384 & 1036 \\
Subtractions & 66 & 33 \\
Divisions & 64 & 32 \\
\hline
\end{tabular}

TABLE 3: Comparison of memory space.

\begin{tabular}{lc}
\hline Method & Memory space used (byte) \\
\hline EKF & 1132 \\
ROEKF & 730 \\
\hline
\end{tabular}

TABLE 4: Motor symbols.

\begin{tabular}{|c|c|c|c|}
\hline DTC & Direct torque control & ROEKF & Reduced order EKF \\
\hline FOC & Field oriented control & SNR & Signal-to-noise ratio \\
\hline EKF & $\begin{array}{c}\text { Extended Kalman } \\
\text { filter }\end{array}$ & PSO & $\begin{array}{l}\text { Particle Swarm } \\
\text { Optimization }\end{array}$ \\
\hline VSD & $\begin{array}{l}\text { Vector space } \\
\text { decomposition }\end{array}$ & 6PIM & $\begin{array}{l}\text { Six-phase induction } \\
\text { motor }\end{array}$ \\
\hline VSI & $\begin{array}{l}\text { Voltage source } \\
\text { inverter }\end{array}$ & DSP & Digital signal processor \\
\hline CPU & $\begin{array}{c}\text { Central processing } \\
\text { unit }\end{array}$ & FPGA & $\begin{array}{l}\text { Field programmable gate } \\
\text { array }\end{array}$ \\
\hline
\end{tabular}

This machine is fed by a six-phase DC-AC VSI. In order to perform the 6PIM closed-loop DTC, the six stator phase currents are sensed using LEM current sensors. Four current sensors are used to sense phase currents of VSI. The outputs of sensors used as parameters are digitized using six 12 bit A/ Ds in the TMS board. The six-phase induction motor is made from a three-phase induction motor by rewinding the stator.

Experimental result of the proposed method in $50 \mathrm{rad} /$ $\mathrm{sec}$ is shown in Figure 4. Six-phase induction motor parameters are shown in Table 1 . The motor speed is $50 \mathrm{rad} / \mathrm{sec}$, and motor load is no load and changed to $1.5 \mathrm{Nm}$ at $t=2.7 \mathrm{sec}$. The proposed EKF algorithm can estimate all parameters perfectly similar to the simulation part. According to results, the proposed algorithm is active after stator resistance variation and load variation. The switched array with six resistance of $7.8 \Omega$ is connected to the stator. One relay put the resistors in the short circuit state. In this state, the stator resistance is equal to Rs. By commanding the switched array resistance, additional resistance can be added or removed to the stator resistance at a specified time.

Comparison of math operation numbers in EKF and ROEKF are shown in Table 2. In this table, various functions used in these algorithms are compared. In ROEKF, the number of math functions is reduced; thus, the execution time of the algorithm is reduced. Despite the reduction in the execution time, the accuracy of algorithm estimation has not changed. In the proposed method, it prevents unnecessary calculation, and this reduces the calculation time.

Also, byte space of memory was reduced in the proposed method. Table 3 shows the comparing of memory space used in EKF and ROEKF methods. According to Tables 2 and 3, the execution time of the algorithm is decreased almost $50 \%$ and used memory space is decreased 35\%. Motor symbols that are used in this paper are shown in Table 4.

\section{Conclusions}

EKF DTC of the six-phase induction motor presented in this paper is able to control the motor in all speed ranges. According to results, the proposed method is active in load variation and parameters change. If the motor speed is low, the proposed method estimates the speed and stator resistance perfectly. If stator resistance is estimated incorrectly, the DTC has an error, and maybe, it is unstable. The proposed ROEKF method has a high speed in estimation. The proposed algorithm can be implemented in a low-cost microprocessor. In the proposed method, the execution time is reduced, and also, the complexity of the system is reduced. The proposed method decreases the execution time and prevents unused computing in DSP and FPGA implementation. The performance of the proposed method is proved by simulations and experimental results.

\section{Data Availability}

The MATLAB files data used to support the findings of this study are available from the corresponding author upon request.

\section{Conflicts of Interest}

The authors declare that they have no conflicts of interest.

\section{Acknowledgments}

This paper was supported in part by the Shaanxi Provincial Special Support Program for Science and Technology Innovation Leader and in part by the Shaanxi Industrial Key Project (2018GY-165).Open Research Fund from Shaanxi Key Laboratory of Complex System Control and Intelligent Information Processing (2020CP01).

\section{References}

[1] E. Levi, R. Bojoi, F. Profumo, H. A. Toliyat, and S. Williamson, "Multiphase induction motor drives-a technology status review," IET Electric Power Applications, vol. 1, no. 4, pp. 489-516, 2007.

[2] R. Yuan and Z. Q. Zhu, "Enhancement of steady-state performance in direct-torque-controlled dual three-phase permanent-magnet synchronous machine drives with modified switching table," IEEE Transactions on Industrial Electronics, vol. 62, no. 6, pp. 3338-3350, 2015.

[3] M. Abdellatif, M. Debbou, I. Slama-Belkhodja, and M. Pietrzak-David, "Simple low-speed sensorless dual DTC for double fed induction machine drive," IEEE Transactions on Industrial Electronics, vol. 61, no. 8, pp. 3915-3922, 2014.

[4] K. D. Hoang, M. Foster, Z.-Q. Zhu, and Y. Ren, "Modified switching-table strategy for reduction of current harmonics in direct torque controlled dual-three-phase permanent magnet synchronous machine drives," IET Electric Power Applications, vol. 9, no. 1, pp. 10-19, 2015. 
[5] H. H. H. Mousa, A.-R. Youssef, and E. E. M. Mohamed, "Model predictive speed control of five-phase permanent magnet synchronous generator-based wind generation system via wind-speed estimation," International Transactions on Electrical Energy Systems, vol. 29, Article ID e2826, 2019.

[6] K. A. Chinmaya and G. K. Singh, "Experimental analysis of various space vector pulse width modulation (SVPWM) techniques for dual three-phase induction motor drive," International Transactions on Electrical Energy Systems, vol. 29, no. 1, Article ID e2678, 2019.

[7] X. Zheng and D. Wang, "Torque regulation of multiphase induction motors under symmetrical fault condition," IEEJ Transactions on Electrical and Electronic Engineering, vol. 12, no. 2, pp. 284-291, 2017.

[8] K. Hatua and V. T. Ranganathan, "Direct torque control schemes for split-phase induction machine," IEEE Transactions on Industry Applications, vol. 41, no. 5, pp. 1243-1254, 2005.

[9] A. Taheri, A. Rahmati, and S. Kaboli, "Energy optimization of field oriented six-phase induction motor drive," Advanced in Electrical and Computer Engineering, vol. 11, no. 2, pp. 107112, 2011.

[10] A. Taheri, A. Rahmati, and S. Kaboli, "Compression of efficiency for different switching tables in six-phase induction motor DTC drive," Journal of Power Electronics, vol. 12, no. 1, pp. 128-135, 2012.

[11] A. Taheri, A. rahmati, and S. Kaboli, "Efficiency improvement in DTC of six-phase induction machine by adaptive gradient descent of flux," IEEE Transactions on Power Electronics, vol. 27, no. 3, pp. 1552-1562, 2012.

[12] M. H. Holakooie, M. Ojaghi, and A. Taheri, "Full-order Luenberger observer based on fuzzy-logic control for sensorless field-oriented control of a single-sided linear induction motor," ISA Transactions, vol. 60, pp. 96-108, 2016.

[13] M. H. Holakooie, M. Ojaghi, and A. Taheri, "Modified DTC of a six-phase induction motor with a second-order slidingmode MRAS-based speed estimator," IEEE Transactions on Power Electronics, vol. 34, no. 1, pp. 600-611, 2019.

[14] H. Masoumkhani and A. Taheri, "PI regulator-based duty cycle control to reduce torque and flux ripples in DTC of sixphase induction motor," IEEE Journal of Emerging and Selected Topics in Power Electronics, 2018.

[15] M. H. Holakooie, M. Ojaghi, and A. Taheri, "Direct torque control of six-phase induction motor with a novel MRASbased stator resistance estimator," IEEE Transactions on Industrial Electronics, vol. 65, no. 10, pp. 7685-7696, 2018.

[16] C. M. Verrelli, A. Savoia, M. Mengoni, R. Marino, P. Tomei, and L. Zarri, "On-line identification of winding resistances and load torque in induction machines," IEEE Transactions on Control Systems Technology, vol. 22, no. 4, pp. 1629-1637, 2014.

[17] R. Antonello, L. Ortombina, F. Tinazzi, and M. Zigliotto, "Online stator resistance tracking for reluctance and interior permanent magnet synchronous motors," IEEE Transactions on Industry Applications, vol. 54, no. 4, pp. 3405-3414, 2018.

[18] C. P. Salomon, W. C. Sant'Ana, L. E. Borges da Silva et al., "Induction motor efficiency evaluation using a new concept of stator resistance," IEEE Transactions on Instrumentation and Measurement, vol. 64, no. 11, pp. 2908-2917, 2015.

[19] Y. Sangsefidi, S. Ziaeinejad, A. Mehrizi-Sani, H. PairodinNabi, and A. Shoulaie, "Estimation of stator resistance in direct torque control synchronous motor drives," IEEE Transactions on Energy Conversion, vol. 30, no. 2, pp. 626-634, 2015.
[20] F. Baneira, A. G. Yepes, Ó. López, and J. Doval-Gandoy, "Estimation method of stator winding temperature for dual three-phase machines based on DC-signal injection," IEEE Transactions on Power Electronics, vol. 31, no. 7, pp. 51415148, 2016.

[21] Z. Yin, G. Li, Y. Zhang, and J. Liu, "Symmetric-strongtracking-extended-Kalman-filter-based sensorless control of induction motor drives for modeling error reduction," IEEE Transactions on Industrial Informatics, vol. 15, no. 2, pp. 650-662, 2019.

[22] M. Barut, R. Demir, E. Zerdali, and R. Inan, "Real-time implementation of Bi input-extended Kalman filter-based estimator for speed-sensorless control of induction motors," IEEE Transactions on Industrial Electronics, vol. 59, no. 11, pp. 4197-4206, 2012.

[23] F. Alonge, T. Cangemi, F. D’Ippolito, A. Fagiolini, and A. Sferlazza, "Convergence analysis of extended kalman filter for sensorless control of induction motor," IEEE Transactions on Industrial Electronics, vol. 62, no. 4, pp. 2341-2352, 2015.

[24] Xu Dong, S. Zhang, and J. Liu, "Very-low speed control of PMSM based on EKF estimation with closed loop optimized parameters," ISA Transactions, vol. 52, no. 6, pp. 835-843, 2013.

[25] O. Aydogmus and S. Sünter, "Implementation of EKF based sensorless drive system using vector controlled PMSM fed by a matrix converter," International Journal of Electrical Power \& Energy Systems, vol. 43, no. 1, pp. 736-743, 2012.

[26] F. Alonge, F. D'Ippolito, A. Fagiolini, and A. Sferlazza, "Extended complex Kalman filter for sensorless control of an induction motor," Control Engineering Practice, vol. 27, pp. 1-10, 2014.

[27] H. Al-Ghossini, F. Locment, M. Sechilariu, L. Gagneur, and C. Forgez, "Adaptive-tuning of extended Kalman filter used for small scale wind generator control," Renewable Energy, vol. 85, pp. 1237-1245, 2016.

[28] A. Taheri and M. Mohammadbeigi, "Speed sensor-less estimation and predictive control of six-phase induction motor using extended Kalman filter," in Proceedings of the the 5th Annual International Power Electronics, Drive Systems and Technologies Conference (PEDSTC 2014), pp. 13-18, Tehran, Italy, February 2014.

[29] S. K. Prince, K. P. Panda, and G. Panda, "Kalman filter variant intelligent control for power quality improvement in photovoltaic active power filter system," International Transactions on Electrical Energy Systems, vol. 30, no. 3, Article ID e12239, 2019.

[30] M. Hinkkanen, L. Harnefors, and J. Luomi, "Reduced-order flux observers with stator-resistance adaptation for speedsensorless induction motor drives," IEEE Transactions on Power Electronics, vol. 25, no. 5, pp. 1173-1183, 2010.

[31] R. Cao, N. Jiang, and M. Lu, "Sensorless control of linear fluxswitching permanent magnet motor based on extended Kalman filter," IEEE Transactions on Industrial Electronics, vol. 67, no. 7, pp. 5971-5979, 2020.

[32] E. Zerdali and M. Barut, "The comparisons of optimized extended Kalman filters for speed-sensorless control of induction motors," IEEE Transactions on Industrial Electronics, vol. 64, no. 6, pp. 4340-4351, 2017.

[33] C. You, J. Lu, and P. Tsiotras, "Nonlinear driver parameter estimation and driver steering behavior analysis for ADAS using field test data," IEEE Transactions on Human-Machine Systems, vol. 47, no. 5, pp. 686-699, 2017. 
[34] A. Taheri, "EKF modeling of field oriewnted control of sixphase induction motor," IEICE Electronics Express, vol. 9, no. 7, pp. 642-647, 2012.

[35] X. Sun, Z. Nie, J. Zhu, Y. Han, and J. Sun, "Speed sensorless control strategy for six-phase linear induction motor based on the dual reduced-dimensional serial extended Kalman filters," IET Power Electronics, vol. 12, no. 14, pp. 3758-3766, 2019.

[36] A. Taheri, H.-P. Ren, and M. H. Holakooie, "Sensorless loss model control of the six-phase induction motor in all speed range by extended Kalman filter," IEEE Access, vol. 8, pp. 118741-118750, 2020.

[37] S. Wang, V. Dinavahi, and J. Xiao, "Multi-rate real-time model-based parameter estimation and state identification for induction motors," IET Electric Power Applications, vol. 7, no. 1, pp. 77-86, 2013.

[38] C.-J. Chiang, Y.-K. Wang, and W.-T Cheng, "EKF-based rotor and stator resistance estimation in speed sensorless control of induction motors," in Proceedings of the American Control Conference (ACC), pp. 1174-1179, Montreal, Canada, June 2012.

[39] R. Demir, M. Barut, R. Yildiz, R. Inan, and E. Zerdali, "EKF based rotor and stator resistance estimations for direct torque control of induction motors," in Proceedings of the International Conference on Optimization of Electrical and Electronic Equipment (OPTIM) \& 2017 Intl Aegean Conference on Electrical Machines and Power Electronics (ACEMP), pp. 376-381, Brasov, Romania, May 2017.

[40] M. Barut, S. Bogosyan, and G. Metin, "Switching EKF technique for rotor and stator resistance estimation in speed sensorless control of IMs," Energy Conversion and Management, vol. 48, no. 12, pp. 3120-3134, 2007. 